(2) Open Access Full Text Article

REVIEW

\title{
Current perspectives in transplant medicine: hypothermic oxygenated perfusion
}

This article was published in the following Dove Press journal:

Transplant Research and Risk Management

10 November 2016

Number of times this article has been viewed

\author{
Sebastian G Michel' \\ Joren C Madsen ${ }^{2,3}$ \\ 'Department of Cardiac Surgery, \\ Ludwig-Maximilians-University, \\ Munich, Germany; ${ }^{2}$ Department of \\ Surgery, Center for Transplantation \\ Sciences, ${ }^{3}$ Division of Cardiac Surgery, \\ Department of Surgery, Massachusetts \\ General Hospital, Boston, MA, USA
}

Abstract: The purpose of this review was to provide an update on hypothermic oxygenated perfusion as a preservation technique for whole organ allografts. Clinical and experimental data in heart, lung, liver, kidney, and pancreas/islet transplantation are summarized with a special emphasis on marginal donors and donation after circulatory death. The rationale behind hypothermic machine perfusion as well as its advantages and disadvantages compared to conventional cold storage and the competing technique, normothermic machine perfusion, are reviewed.

Keywords: organ transplantation, organ preservation, hypothermic perfusion

\section{Introduction}

Organ transplantation remains the most effective way to treat organ failure. Unfortunately, the gap between available donor organs and potential recipients is wide and becoming wider (www.organdonor.gov). Therefore, various attempts have been made to increase the donor pool, for example, by accepting longer ischemic times or by using extended criteria donors (ECD) whose organs may be of inferior quality due to age or disease. Using donors after circulatory death (DCD) represents another way to increase the pool of transplantable organs but is, by definition, associated with a period of harmful warm ischemia time unlike organs retrieved from donors after brain death (DBD). Machine perfusion (MP) of donor organs (either hypothermic machine perfusion [HMP] or normothermic machine perfusion [NMP]) attempts to minimize and even compensate for harmful effects of warm and cold ischemia in order to improve organ quality and ultimately transplant outcomes while at the same time, increasing the number of potential donors.

Static cold storage (CS) in a suitable solution like University of Wisconsin (UW) or Celsior on ice, remains the standard method to preserve organs of good quality after DBD. However, the revival of MP in kidney transplantation has led to a $37 \%$ increased usage of this technique in the USA. ${ }^{1}$ Not only can MP mitigate some of the negative effects of ischemia on the donor organ, but it is also a helpful tool in evaluating the overall quality of the organ before it is transplanted. Moreover, in some cases, MP can provide a beneficial period of physiologic resuscitation which can convert a compromised organ into one that is suitable for transplantation. ${ }^{2}$ This review will provide an update on current clinical applications and latest experimental findings of MP technology in organ transplantation with a focus on "hypothermic oxygenated perfusion".
Correspondence: Joren C Madsen Center for Transplantation Sciences, Massachusetts General Hospital-East, Charlestown Navy Yard, Building I49,

I3th Street, Charlestown,

MA 02129-2020, USA

$\mathrm{Tel}+\mathrm{I} 6177266506$

Fax + I 6177264067

Email jcmadsen@mgh.harvard.edu
Transplant Research and Risk Management 2016:8 25-30 


\section{HMP vs static CS}

After procurement, the donor organ undergoes a period of ischemia because it is disconnected from the blood supply and therefore from oxygen and nutrients. Static CS at the recommended $4^{\circ} \mathrm{C}$ reduces the oxygen demand and the metabolism approximately 12 -fold ${ }^{3}$ but not completely. This results in ongoing adenosine triphosphate (ATP)-depletion, a change from aerobic to anaerobic metabolism and the production of lactate depending on the length of the ischemic time. ${ }^{4}$ The result of the imbalance between supply and demand within the ischemic organ and its subsequent reperfusion lead to activation of the immune system and, ultimately, the result is cell death by apoptosis and necrosis, known as ischemiareperfusion injury. ${ }^{5}$ Some organs are more sensitive toward ischemia (heart) than others (liver, kidney). Hypothermic oxygenated perfusion, that is, the ex vivo perfusion of donor organs on a machine at low temperatures prior to transplant (as it is defined by Taylor and Baicu') is meant to prevent ATP depletion by providing oxygen and nutrients while eliminating toxic metabolic by-products such as lactate. In this way, ischemia-reperfusion injury is reduced and overall clinical results improved., ${ }^{4,7-9}$ Another, often overlooked advantage of HMP over CS is the fact that the temperature can be precisely regulated to remain in the desirable range of $4^{\circ} \mathrm{C}-8^{\circ} \mathrm{C}$. In static $\mathrm{CS}$ on ice, temperatures often drop too low $\left(0^{\circ} \mathrm{C}-2^{\circ} \mathrm{C}\right)$ resulting in tissue freezing ${ }^{10}$ and more severe tissue injury upon reperfusion. ${ }^{11}$

\section{The importance of oxygenation}

There is an ongoing debate on the optimum oxygen requirement of donor organs during hypothermia. On the one hand, we know that cellular metabolism is halved for every $10^{\circ} \mathrm{C}$ reduction in temperature (van't Hoff's rule). For example, when HMP is performed at $7^{\circ} \mathrm{C}$ cellular metabolism is only $12.5 \%$ compared to normothermia. However, if too much oxygen is delivered during hypothermia, free radicals are generated, which can lead to tissue damage. ${ }^{12}$ Conversely, there is clear evidence that ATP levels in the tissue can only be preserved when oxygen is supplied, even at low temperatures. Thus, "oxygenated" HMP can avoid oxidative stress for the donor organ. ${ }^{13,14}$

Interestingly, three different preclinical studies using a porcine kidney transplant model found a difference in the effects of oxygenation in MP depending on whether the organ was procured from a heart-beating donor or from a DCD donor. When heart-beating donors were used oxygenated MP was actually inferior to anoxic MP as evidenced in the lower creatinine clearance in the oxygenated group. ${ }^{15}$
However, in the DCD setting, associated with a greater period of warm ischemia, creatinine clearance was higher, ${ }^{16}$ peak creatinine levels were lower after kidney transplantation and there was less interstitial fibrosis in the 3-month follow-up when oxygenated MP was applied. ${ }^{17}$ This might be explained by the fact that oxygenated MP is more beneficial in organs undergoing a prolonged warm ischemia. ${ }^{2}$ It could also explain why in Watson's multicenter randomized controlled trial of DCD-kidney transplantation, using "nonoxygenated" MP no statistically significant reduction in delayed graft function (DGF) could be shown when compared to static CS. ${ }^{9}$

\section{HMP of the kidney}

HMP of the kidney was originally used in the 1960s by Belzer's group ${ }^{18}$ but the machine was so huge that the ease and low cost of static CS were superior, particularly when UW solution became available. ${ }^{19} \mathrm{~A}$ revival of nonoxygenated HMP has been seen recently as more and more marginal kidneys are accepted for transplantation to meet the demand of the fast growing numbers of recipients on the waiting list. These ECD include old donors with impaired kidney function as well as DCD donors. It has been shown that transplantation of such kidneys has a survival benefit for the patient compared to dialysis alone. ${ }^{20}$ There is solid evidence that the rate of DGF, defined as need for dialysis in the first week posttransplant, is lower after nonoxygenated HMP compared to conventional CS. This is true for standard criteria (good quality, brain dead) donors, ${ }^{21,22} \mathrm{ECD}^{23}$ and $\mathrm{DCD}^{8,22}$

In these studies, nonoxygenated HMP was applied. Testing the quality of the graft during MP by measuring flow and resistance could not have been shown to predict transplant outcome in some studies ${ }^{24-26}$ but elevated resistance was associated with DGF and graft failure at 1 year in the randomized Eurotransplant trial. ${ }^{27}$

The therapeutic approach of adding substrates to improve the graft quality during HMP is still under investigation. It could be shown in a porcine model that propofol, acting as an antioxidant, was able to reduce renal vascular resistance and improve renal function posttransplant. ${ }^{28}$

\section{HMP of the liver}

Clinical experience with liver HMP is limited. Three transplant centers (Columbia using nonoxygenated HMP, Groningen and Zurich using oxygenated HMP) currently use this technique $^{29}$ as an end-ischemic perfusion after CS (i.e., not continuous starting after the organ procurement, but HMP after CS before implanting the liver). The initial report of 20 standard DBD human livers showed less enzyme release, less 
early graft dysfunction, and a shorter hospital stay compared to control when nonoxygenated HMP was used. ${ }^{30}$ Guarrera et al also investigated marginal DBD donors and found less biliary complications when nonoxygenated HMP was applied compared to $\mathrm{CS}$ alone. ${ }^{31}$ The group from Zurich studied DCD livers using oxygenated HMP (liver assist, Figure 1) and showed less biliary complications and therefore better graft survival. ${ }^{7,32}$ Lastly, the Groningen group could show less biliary strictures in DCD livers using oxygenated HMP (liver assist, Figure 1). ${ }^{33}$ Randomized studies are underway to investigate this preliminary data further. There is still debate over whether perfusion should only be performed through the portal vein or through the portal vein and the hepatic artery. ${ }^{29}$

\section{HMP of the heart}

Registry data of the International Society for Heart and Lung Transplantation show that ischemia of more than 200 minutes is associated with a higher mortality after heart transplantation. ${ }^{34}$ Therefore, it is critical to find ways to protect against longer ischemic times for the heart. Not only would extending the safe ischemic period time permit the transportation of hearts procured from more distant sites, but it could also enable human leukocyte antigen (HLA)-matching between donor and recipient. HLA-matching is not routine in heart transplantation at the moment because of the time constraints, however, it has been shown to improve survival in some reports. ${ }^{35} \mathrm{Cur}-$

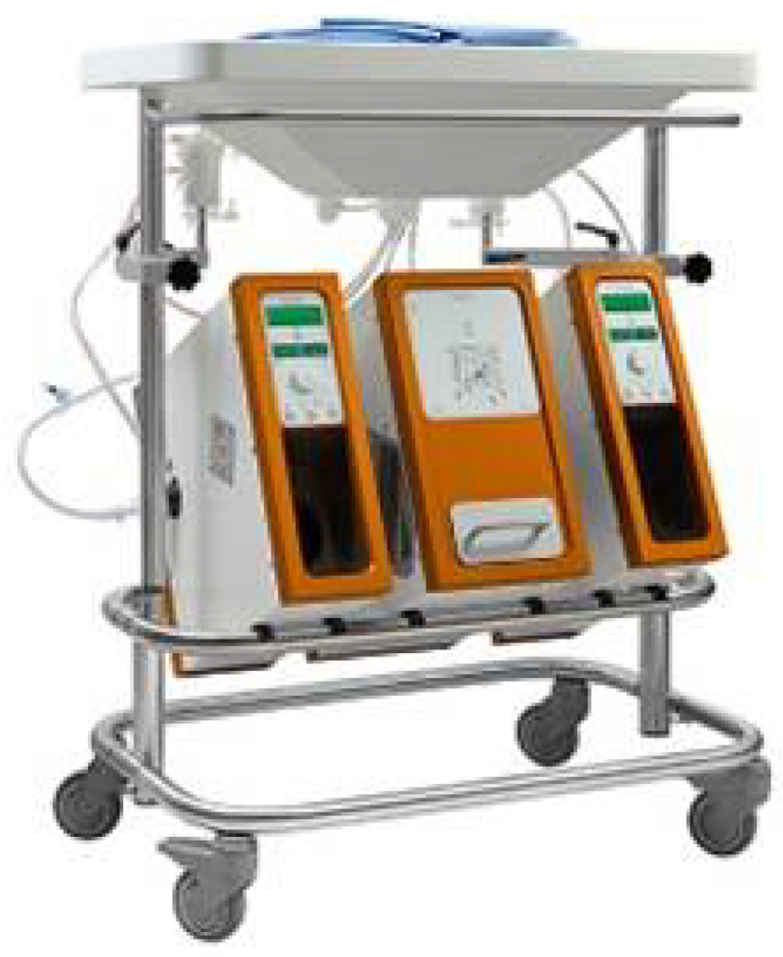

Figure I Liver assist (Organ Assist, Groningen, the Netherlands).

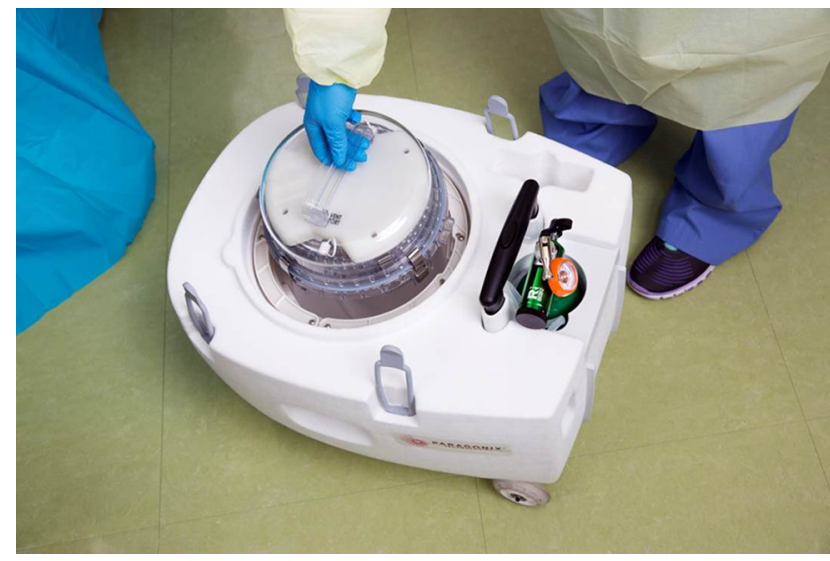

Figure 2 Paragonix Sherpa ${ }^{\mathrm{TM}}$ cardiac transport system (Braintree, MA, USA).

rently, only "normothermic" perfusion is used clinically (see Normothermic machine perfusion (NMP) section). There is, however, preclinical experimental data showing that hypothermic oxygenated MP is beneficial for donor hearts.

Using a porcine model, our group showed that oxygenated HMP using the Paragonix Sherpa ${ }^{\mathrm{TM}}$ Cardiac Transport System (Figure 2) led to a better preserved cell structure of the myocytes after reperfusion of the donor heart after the currently accepted ischemic period of 4 hours and also after an extended ischemic period of 12 hours. ${ }^{36,37}$ Furthermore, we demonstrated that the perfused hearts had less depletion of tissue ATP stores and had preserved architecture of the mitochondria (Figure 3 ). There was also a nonsignificant trend toward lower endothelin-1 levels (marker for endothelial dysfunction) and less apoptosis in TUNEL-staining in perfused hearts after 12 hours compared to 12 hours conventional CS in Celsior. ${ }^{37}$ These benefits could potentially translate to better short-term (less primary graft failure) and long-term (less cardiac allograft vasculopathy) clinical outcomes after heart transplantation. We are currently working on finding the optimal perfusion pressure and flow to avoid edema formation on the one hand but to provide enough oxygen and nutrients on the other. ${ }^{37}$

In a canine study, hearts transplanted after 24 hours of HMP were comparable to 4 hours statically stored hearts in terms of duration of cardiopulmonary bypass support, survival, inotropic support, and cardiac output. ${ }^{38}$ Another study in dogs showed superior systolic functional recovery on a Langendorff system after 24 hours of HMP compared to 8 hours of CS. ${ }^{11}$ A similar preclinical model found superior functional recovery after HMP but also reduced caspase-3 (marker for apoptosis), reduced malondialdehyde (marker for oxidative stress), and reduced endothelin-1-levels (marker for endothelial dysfunction) in the heart tissue as well as higher ATP levels compared to CS. ${ }^{39}$ 
A

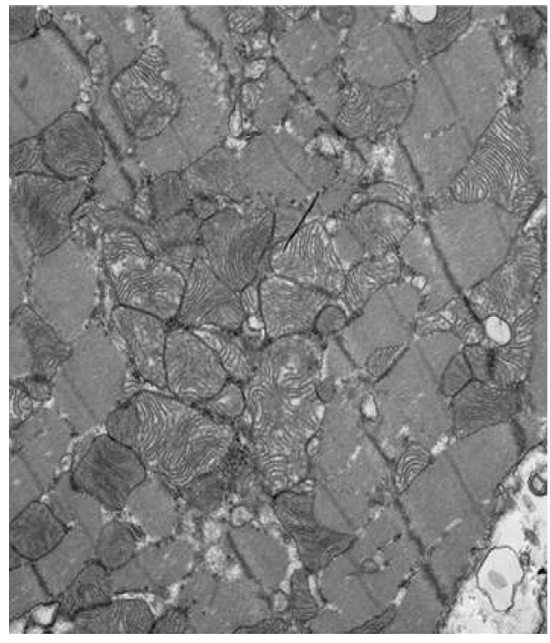

B

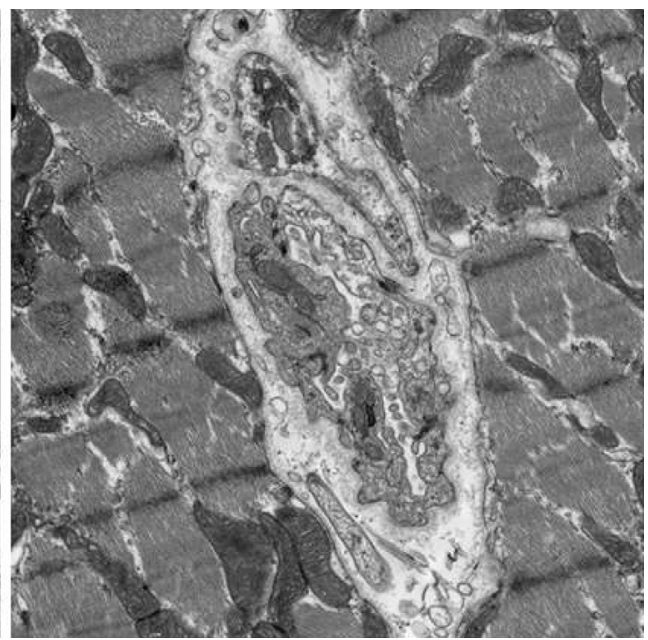

Figure 3 Electron microscopy of porcine hearts after (A) 12 hours of oxygenated HMP or (B) 12 hours of CS.

Notes: (A) Oxygenated HMP preserves the mitochondria which remain round and intact while (B) CS shows flattened mitochondria of irregular shape which mirrors ATP depletion. Magnification $\times$ I I,000. Adapted with permission from Michel SG, La Muraglia GM 2nd, Madariaga ML, et al. Twelve-hour hypothermic machine perfusion for donor heart preservation leads to improved ultrastructural characteristics compared to conventional cold storage. Ann Transplant. 20I5;20:46I-468. ${ }^{37}$

Abbreviations: CS, cold storage; HMP, hypothermic machine perfusion; ATP, adenosine triphosphate.

\section{HMP of the lung}

Hypothermic oxygenated MP of lungs has only been studied in preclinical experimental models. Using a DCD-lung transplant model in dogs, a positive effect of HMP was shown compared to conventional CS alone. Lungs showed less ischemia-reperfusion injury histologically, less proinflammatory cytokine levels, and higher tissue ATP levels after reperfusion using HMP with Steen solution at $10^{\circ} \mathrm{C} .{ }^{40}$ The authors hypothesized that HMP is particularly helpful for the wash-out of microthrombi that are present in the donor lung before transplantation.

\section{HMP of the pancreas}

Until now, HMP has not been used in human pancreas transplantation. Although it has been shown to be feasible and safe in animal models, an advantage compared to CS could not be shown. ${ }^{41-45}$ HMP causes graft edema and congestion followed by venous thrombosis and graft failure despite attempts to adjust flow and pressure. ${ }^{4}$ However, there may be a theoretical advantage of edema formation in perfused pancreata because islets separate more easily from the extracellular matrix in perfused pancreata compared to CS and this can yield a greater number of the islets. ${ }^{4}$

\section{Normothermic machine perfusion (NMP)}

NMP with blood undoubtedly comes closest to the physiological state of the donor organ. Aerobic metabolism can continue outside the body and there is no ATP depletion.
The disadvantage of NMP is its complexity and its cost compared to CS or HMP. Oxygen and energy demands are much higher at $37^{\circ} \mathrm{C}$, and therefore, technical failure leads to ischemic damage immediately. MP at hypothermia has much more room for error. In addition, normothermia has a higher risk of transmitting infection with the donor organ, as bacteria grow faster. ${ }^{4}$ Nevertheless, several reports have shown positive and promising results of this technique for different organs.

In clinical lung transplantation, normothermic perfusion using the Organ Care System ${ }^{\text {TM }}$ (Transmedics, Andover, MA, USA) has been shown to be safe and effective in a pilot study of 12 patients. ${ }^{46} \mathrm{~A}$ randomized multicenter trial (INSPIRE) has been completed in 2014, and preliminary data presented at the International Society for Heart and Lung Transplantation Meeting in Montreal 2013 showed noninferiority compared to conventional CS in terms of the combined primary endpoint 30-day survival and absence of primary graft dysfunction grade 3 after 72 hours. The other established technique to preserve donor lungs is conventional CS followed by ex vivo lung perfusion (EVLP) to improve the quality of the donor lung. This technique is particularly helpful when DCD-lungs with inferior initial quality are being evaluated for transplant. It has been shown that transplantation of these high-risk donor lungs using EVLP led to similar results to those obtained with conventionally selected lungs without EVLP. ${ }^{47} \mathrm{EVLP}$ is a clinical routine in some experienced lung transplant centers (e.g., Toronto and Lund), and is a helpful tool to evaluate the quality of marginal donor organs particularly for DCD. ${ }^{48}$ In clinical heart transplantation, NMP with the Organ Care 
System has been shown to be noninferior to conventional $\mathrm{CS}^{49}$ (PROCEED II trial, primary endpoint 30-day graft and patient survival). Importantly, the Organ Care System has also enabled the most recent successful cases of DCD heart transplantation in Australia ${ }^{50}$ and the UK. In kidney transplantation, Nicholson and Hosgood have described a very low DGF rate of only $5.6 \%$ after NMP, despite the fact that they used marginal donors. ${ }^{51}$ The rate of DGF in these 18 patients is significantly lower than the $20.8 \%$ seen in the Eurotransplant trial using HMP.2 ${ }^{22}$ The OCS ${ }^{\mathrm{TM}}$ Liver PROTECT clinical trial is currently initiating and Peter Friend's group from Oxford and Birmingham has just published the results of a Phase I study with 20 patients showing that NMP for liver transplantation is safe and feasible. ${ }^{52}$ Using the OrganOx metra ${ }^{\circledR}$, they could even show significantly lower aspartate aminotransferase levels in the first 7 days in the NMP group compared to CS. Finally, there is one report on the successful use of NMP for quality assessment of discarded human pancreases (insulin secretion and amylase levels). ${ }^{53}$ Based on these data, normothermic perfusion appears to be highly efficient and may represent the future of organ preservation.

\section{Conclusion}

In conclusion, HMP is superior to the current standard of static CS of donor organs and can increase the donor pool by enabling the surgeon to more aggressively accept marginal donors and longer preservation times. For kidney transplantation, controlled randomized trials have shown that HMP improves outcomes by reducing DGF. The novel emerging technology of NMP seems to be promising in heart, lung, liver, and kidney transplantation and, although expensive, will probably be the future of organ preservation, as it is the most physiological way to preserve a donor organ.

\section{Acknowledgment}

This work was supported in part by a Small Business Innovation Research (SBIR) grant (R34HL115852) from the National Heart, Lung, and Blood Institute of the National Institutes of Health (NIH) to the Paragonix Corporation.

\section{Disclosure}

The authors report no conflicts of interest in this work.

\section{References}

1. Goldstein MJ, Lubezky N, Yushkov Y, Bae C, Guarrera JV. Innovations in organ donation. Mt Sinai J Med. 2012;79(3):351-364.

2. Cannon RM, Franklin GA. Machine perfusion for improving outcomes following renal transplant: current perspectives. Trans Res Risk Manag. 2016;8:1-7.
3. Belzer FO, Southard JH. Principles of solid-organ preservation by cold storage. Transplantation. 1988;45(4):673-676.

4. Henry SD, Guarrera JV. Protective effects of hypothermic ex vivo perfusion on ischemia/reperfusion injury and transplant outcomes. Transplant Rev (Orlando). 2012;26(2):163-175.

5. Eltzschig HK, Eckle T. Ischemia and reperfusion - from mechanism to translation. Nat Med. 2011;17(11):1391-1401.

6. Taylor MJ, Baicu SC. Current state of hypothermic machine perfusion preservation of organs: the clinical perspective. Cryobiology. 2010;60(3 Suppl):S20-S35.

7. Dutkowski P, Polak WG, Muiesan P, et al. First comparison of hypothermic oxygenated perfusion versus static cold storage of human donation after cardiac death liver transplants: an international-matched case analysis. Ann Surg. 2015;262(5):764-770; discussion 770-771.

8. Jochmans I, Moers C, Smits JM, et al. Machine perfusion versus cold storage for the preservation of kidneys donated after cardiac death: a multicenter, randomized, controlled trial. Ann Surg. 2010;252(5): 756-764.

9. Watson CJ, Wells AC, Roberts RJ, et al. Cold machine perfusion versus static cold storage of kidneys donated after cardiac death: a UK multicenter randomized controlled trial. Am J Transplant. 2010;10(9): 1991-1999.

10. Michel SG, LaMuraglia Ii GM, Madariaga ML, Anderson LM. Innovative cold storage of donor organs using the Paragonix Sherpa Pak devices. Heart Lung Vessel. 2015;7(3):246-255.

11. Poston RS, Gu J, Prastein D, et al. Optimizing donor heart outcome after prolonged storage with endothelial function analysis and continuous perfusion. Ann Thorac Surg. 2004;78(4):1362-1370; discussion 1362-1370.

12. Fuller BJ, Gower JD, Green CJ. Free radical damage and organ preservation: fact or fiction? A review of the interrelationship between oxidative stress and physiological ion disbalance. Cryobiology. 1988;25(5):377-393.

13. van der Plaats A, t Hart NA, Verkerke GJ, Leuvenink HG, Ploeg RJ, Rakhorst G. Hypothermic machine preservation in liver transplantation revisited: concepts and criteria in the new millennium. Ann Biomed Eng. 2004;32(4):623-631.

14. Schlegel A, Kron P, Graf R, Clavien PA, Dutkowsk P. Hypothermic Oxygenated Perfusion (HOPE) downregulates the immune response in a rat model of liver transplantation. Ann Surg. 2014;260(5):931-937; discussion 937-938.

15. Gallinat A, Paul A, Efferz P, Lüer B, Swoboda S, Hoyer D, Minor T. Role of oxygenation in hypothermic machine perfusion of kidneys from heart beating donors. Transplantation. 2012;94(8):809-813.

16. Hoyer DP, Gallinat A, Swoboda S, Wohlschlaeger J, Rauen U, Paul A, Minor T. Influence of oxygen concentration during hypothermic machine perfusion on porcine kidneys from donation after circulatory death. Transplantation. 2014;98(9):944-950.

17. Thuillier R, Allain G, Celhay O, et al. Benefits of active oxygenation during hypothermic machine perfusion of kidneys in a preclinical model of deceased after cardiac death donors. J Surg Res. 2013; 184(2):1174-1181.

18. Belzer FO, Ashby BS, Gulyassy PF, Powell M. Successful seventeenhour preservation and transplantation of human-cadaver kidney. $N$ Engl J Med. 1968;278(11):608-610.

19. Belzer FO, Southard JH. The future of kidney preservation. Transplantation. 1980;30(3):161-165.

20. Ojo AO, Hanson JA, Meier-Kriesche H, et al. Survival in recipients of marginal cadaveric donor kidneys compared with other recipients and wait-listed transplant candidates. J Am Soc Nephrol. 2001;12(3): 589-597.

21. Shah AP, Milgrom DP, Mangus RS, Powelson JA, Goggins WC, Milgrom ML. Comparison of pulsatile perfusion and cold storage for paired kidney allografts. Transplantation. 2008;86(7):1006-1009.

22. Moers C, Smits JM, Maathuis MH, et al. Machine perfusion or cold storage in deceased-donor kidney transplantation. $N$ Engl $\mathrm{J}$ Med. 2009;360(1):7-19. 
23. Treckmann J, Moers C, Smits JM, et al. Machine perfusion versus cold storage for preservation of kidneys from expanded criteria donors after brain death. Transpl Int. 2011;24(6):548-554.

24. Mozes MF, Skolek RB, Korf BC. Use of perfusion parameters in predicting outcomes of machine-preserved kidneys. Transplant Proc. 2005;37(1):350-351.

25. Sonnenday CJ, Cooper M, Kraus E, Gage F, Handley C, Montgomery RA. The hazards of basing acceptance of cadaveric renal allografts on pulsatile perfusion parameters alone. Transplantation. 2003;75(12): 2029-2033.

26. Guarrera JV, Goldstein MJ, Samstein B, et al. 'When good kidneys pump badly': outcomes of deceased donor renal allografts with poor pulsatile perfusion characteristics. Transpl Int. 2010;23(4):444-446.

27. Jochmans I, Moers C, Smits JM, et al. The prognostic value of renal resistance during hypothermic machine perfusion of deceased donor kidneys. Am J Transplant. 2011;11(10):2214-2220.

28. Snoeijs MG, Vaahtera L, de Vries EE, et al. Addition of a water-soluble propofol formulation to preservation solution in experimental kidney transplantation. Transplantation. 2011;92(3):296-302.

29. Schlegel A, Kron P, Dutkowski P. Hypothermic machine perfusion in liver transplantation. Curr Opin Organ Transplant. 2016;21(3): 306-314.

30. Guarrera JV, Henry SD, Samstein B, et al. Hypothermic machine preservation in human liver transplantation: the first clinical series. $\mathrm{Am} \mathrm{J}$ Transplant. 2010;10(2):372-381.

31. Guarrera JV, Henry SD, Samstein B, et al. Hypothermic machine preservation facilitates successful transplantation of "orphan" extended criteria donor livers. Am J Transplant. 2015;15(1):161-169.

32. Dutkowski P, Schlegel A, de Oliveira M, Müllhaupt B, Neff F, Clavien PA. HOPE for human liver grafts obtained from donors after cardiac death. J Hepatol. 2014;60(4):765-772.

33. Van Rijn R, Matton APM, Westerkamp AC, et al. First clinical series of end-ischemic hypothermic oxygenated machine perfusion via hepatic artery and portal vein in donation after circulatory death liver transplantation. Abstract ILTS Chicago. 2015;99:86.

34. Taylor DO, Stehlik J, Edwards LB, et al. Registry of the International Society for Heart and Lung Transplantation: Twenty-Sixth Official Adult Heart Transplant Report - 2009. J Heart Lung Transplant. 2009; 28(10):1007-1022.

35. Kaczmarek I, Deutsch MA, Rohrer ME, et al. HLA-DR matching improves survival after heart transplantation: is it time to change allocation policies? J Heart Lung Transplant. 2006;25(9):1057-1062.

36. Michel SG, La Muraglia GM 2nd, Madariaga ML, et al. Preservation of donor hearts using hypothermic oxygenated perfusion. Ann Transplant. 2014;19:409-416.

37. Michel SG, La Muraglia GM 2nd, Madariaga ML, et al. Twelve-hour hypothermic machine perfusion for donor heart preservation leads to improved ultrastructural characteristics compared to conventional cold storage. Ann Transplant. 2015;20:461-468.
38. Fitton TP, Barreiro CJ, Bonde PN, Wei C, Gage F, Rodriguez R, Conte JV. Attenuation of DNA damage in canine hearts preserved by continuous hypothermic perfusion. Ann Thorac Surg. 2005;80(5):1812-1820.

39. Ozeki T, Kwon MH, Gu J, et al. Heart preservation using continuous ex vivo perfusion improves viability and functional recovery. Circ J. 2007;71(1):153-159.

40. Nakajima D, Chen F, Okita K, et al. Reconditioning lungs donated after cardiac death using short-term hypothermic machine perfusion. Transplantation. 2012;94(10):999-1004.

41. Alteveer RJ, Jaffe MJ, Van Dam J. Hemodynamics and metabolism of the in vivo vascularly isolated canine pancreas. Am J Physiol. 1979;236(6):E626-E632.

42. Florack G, Sutherland DE, Cavallini M, Najarian JS. Technical aspects of segmental pancreatic autotransplantation in dogs. Am J Surg. 1983;146(5):565-574.

43. Squifflet JP, Sutherland DE, Rynasiewicz JJ, Bentley FC, Florack G, Najarian JS. Technical aspects of segmental pancreatic grafting in rats. Microsurgery. 1983;4(1):61-66.

44. Tersigni R, Toledo-Pereyra LH, Pinkham J, Najarian JS. Pancreaticoduodenal preservation by hypothermic pulsatile perfusion for twenty-four hours. Ann Surg. 1975;182(6):743-748.

45. Toledo-Pereyra LH, Valgee KD, Castellanos J, Chee M. Hypothermic pulsatile perfusion: its use in the preservation of pancreases for 24 to 48 hours before islet cell transplantation. Arch Surg. 1980;115(1):95-98.

46. Warnecke G, Moradiellos J, Tudorache I, et al. Normothermic perfusion of donor lungs for preservation and assessment with the Organ Care System Lung before bilateral transplantation: a pilot study of 12 patients. Lancet. 2012;380(9856):1851-1858.

47. Cypel M, Yeung JC, Liu M, et al. Normothermic ex vivo lung perfusion in clinical lung transplantation. NEngl J Med. 2011;364(15):1431-1440.

48. Sanchez PG, Bittle GJ, Burdorf L, Pierson RN 3rd, Griffith BP. State of art: clinical ex vivo lung perfusion: rationale, current status, and future directions. J Heart Lung Transplant. 2012;31(4):339-348.

49. Ardehali A, Esmailian F, Deng M, et al. Ex-vivo perfusion of donor hearts for human heart transplantation (PROCEED II): a prospective, open-label, multicentre, randomised non-inferiority trial. Lancet. 2015;385(9987):2577-2584.

50. Dhital KK, Iyer A, Connellan M, et al. Adult heart transplantation with distant procurement and ex-vivo preservation of donor hearts after circulatory death: a case series. Lancet. 2015;385(9987):2585-2591.

51. Nicholson ML, Hosgood SA. Renal transplantation after ex vivo normothermic perfusion: the first clinical study. Am JTransplant. 2013;13(5): 1246-1252.

52. Ravikumar R, Jassem W, Mergental H, et al. Liver transplantation after ex vivo normothermic machine preservation: a phase 1 (First-in-Man) clinical trial. Am J Transplant. 2016;16(6):1779-1787.

53. Barlow AD, Hamed MO, Mallon DH, et al. Use of ex vivo normothermic perfusion for quality assessment of discarded human donor pancreases. Am J Transplant. 2015;15(9):2475-2482.
Transplant Research and Risk Management

\section{Publish your work in this journal}

Transplant Research and Risk Management is an international, peerreviewed open access journal focusing on all aspects of transplantation and risk management to achieve optimal outcomes in the recipient improving survival and quality of life. The manuscript management system is completely online and includes a very quick and fair peer-review system,
Dovepress

which is all easy to use. Visit http://www.dovepress.com/testimonials.php to read real quotes from published authors. 